\title{
A Wideband Antenna with Circular and Rectangular Shaped Slots for Mobile Phone Applications
}

\author{
Wei-Hua Zong, ${ }^{1}$ Xiao-Mei Yang, ${ }^{1}$ Xia Xiao, ${ }^{1}$ Shan-Dong Li, ${ }^{2}$ \\ Xiang-Yang Wei, ${ }^{3}$ Zhe-Jun Jin, ${ }^{1}$ and Xiao-Yun $\mathbf{Q u}^{4}$ \\ ${ }^{1}$ School of Electronics and Information, Qingdao University, Qingdao 266071, China \\ ${ }^{2}$ College of Physics and Key Laboratory of Photonics Materials and Technology in University of Shandong, \\ Laboratory of Fiber Materials and Modern Textile, The Growing Base for State Key Laboratory, Qingdao University, \\ Qingdao 266071, Shandong, China \\ ${ }^{3}$ RF Department, Goertek Inc., Qingdao 266071, China \\ ${ }^{4}$ No. 513 Institute, No. 5 Academy, China Aerospace Science and Technology Corporation, Yantai 264000, China
}

Correspondence should be addressed to Wei-Hua Zong; weihuazong@126.com

Received 14 April 2016; Revised 16 June 2016; Accepted 22 June 2016

Academic Editor: Renato Cicchetti

Copyright (C) 2016 Wei-Hua Zong et al. This is an open access article distributed under the Creative Commons Attribution License, which permits unrestricted use, distribution, and reproduction in any medium, provided the original work is properly cited.

\begin{abstract}
A wideband slot antenna for mobile phone applications is proposed. The antenna has two slots with open ends etched on the opposite edges of the ground plane. The main slot, of total length of $59 \mathrm{~mm}$, is composed of a rectangle connected to a circle having radius of $5 \mathrm{~mm}$. Another slot, having a rectangular shape with width of $2.8 \mathrm{~mm}$ and length of $26 \mathrm{~mm}$, is employed to enhance the antenna bandwidth. The slots are fed by means of a rectangular monopole connected to a circular patch joined to a bent $50 \Omega$ microstrip transmission line forming two right angles. To obtain a wideband impedance matching, the upper edge of the monopole and a part of the feeding line evolve along the top edge of the two slots. To reduce the antenna size, the upper part of the board above the slot (just $3 \mathrm{~mm}$ from the slot) is folded vertically to the ground plane. The measured bandwidth of the antenna is $0.698-1.10 \mathrm{GHz}$ and 1.64-2.83 GHz covering LTE700/2300/2500, GSM850/900/1800/1900, and UMTS bands.
\end{abstract}

\section{Introduction}

Antennas for modern smart mobile phones are characterized by a low profile and multiple frequency bands. The widely used frequency bands for mobile communication include LTE700 (698-787 MHz), GSM850 (824-894 MHz), GSM900 (880-960 MHz), GSM1800 (1710-1880 MHz), GSM1900 (1850-1990 MHz), UMTS (1920-2170 MHz), LTE2300 (2305$2400 \mathrm{MHz})$, and LTE2500 (2500-2690 MHz). The conventional mobile phone antennas include three basic types of PIFAs (planar inverted-F antennas), printed monopole antennas, and printed slot antennas. With several limitations concerning the antenna size, it is not easy to design an antenna to cover the frequency bands $698-960 \mathrm{MHz}$ and $1710-2690 \mathrm{MHz}$ simultaneously. Several techniques based on conventional handset antennas, including the impedance matching circuit using lumped components [1-3], the reconfigurable antenna using PIN diodes [4-7], and the tunable antenna using tunable capacitors [8], have been employed for the antenna design. These techniques involve lumped components or DC feeding system, which increase the complexity of the design and the realization cost.

In this paper, we address the design of a printed slot antenna for mobile phones. The most popularly used slot antennas adopt rectangular shape as the basic unit to form the desired shaped slot [9-14]. The antenna in [9] is composed of two open-ended slots cut at the same edge of the system ground plane. One of the slots has a rectangular shape and the other has an L shape. The bandwidth of the antenna is narrow and consequently only the frequency bands of the GSM850 and GSM900 are covered in the lower frequency band. The antenna in [10] consists of a C-shaped and an Lshaped slot occupying a $21 \times 45 \mathrm{~mm}^{2}$ area on the ground plane. The slots in $[9,10]$ are both fed by $50 \Omega$ microstrip 


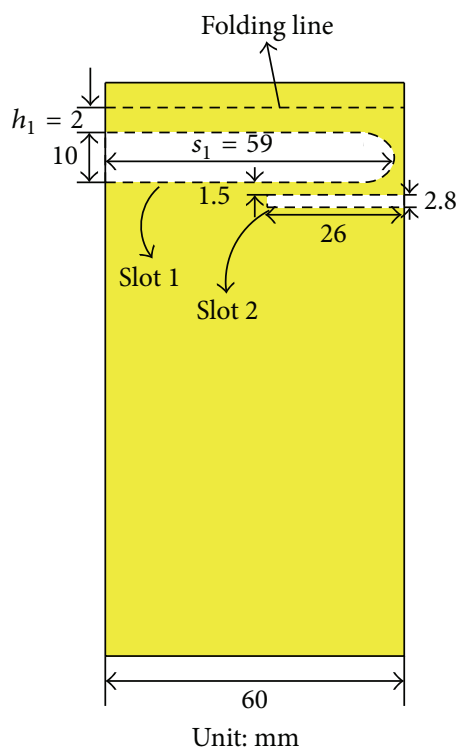

Ground plane with slot (bottom side of the substrate)

(a)

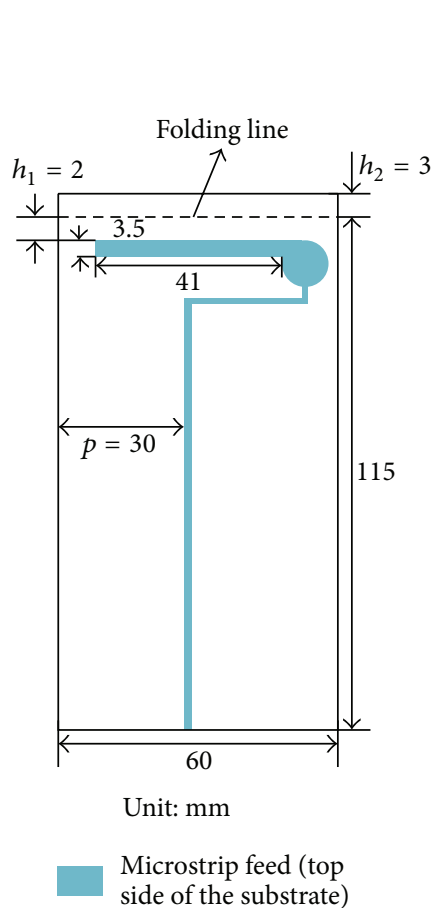

(b)

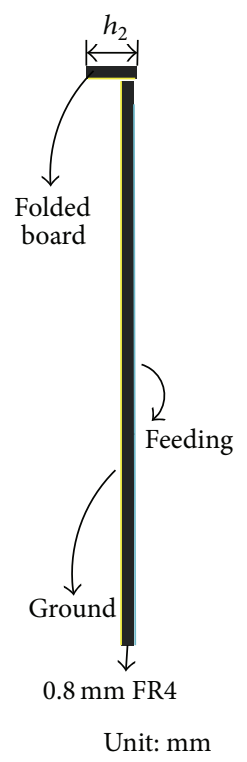

Ground plane with slot (bottom side of the substrate) Microstrip feed (top side of the substrate)

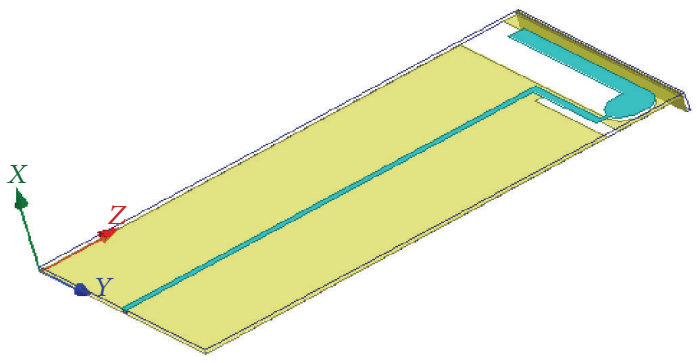

(c)

(d)

Figure 1: Configuration of the proposed antenna. (a) Bottom view. (b) Top view. (c) Side view. (d) 3D view.

line with straight shape. The slot antennas proposed in recent years employ suitable techniques for the excitation of the radiating slots [11-14]. Two monopoles connected to a $50 \Omega$ microstrip line to feed two rectangular slots opened at the same edge of system board are proposed in [11]. L-shaped feeding structures are adopted to feed rectangular slots in $[12,13]$. A simple printed monopole slot antenna and a Cshaped strip connected orthogonal to the bottom edge of the system ground plane are proposed in [12] for pentaband operation of a mobile handset. A simple printed monopole slot antenna with two parasitic shorted strips for pentaband wireless wide area network operation in a slim mobile phone is presented in [13], while in [14] a monopole with multiple branches and a parasitic ground strip with an L-shaped open slot are employed to realize an antenna for a multiband mobile handset.

A mobile antenna employing a circular radiating slot, having a frequency band ranging between 1.73 and $11 \mathrm{GHz}$, obtained by slightly modifying the UWB antenna presented in [15], was proposed in [16]. A better performance is achieved by the antenna presented in [17], which, adopting an electromagnetic band gap (EBG) structure integrated in the ground plane, allows covering the frequency band of 1.53$11 \mathrm{GHz}$. Finally, inverted L-shaped slot and feeding structures have been employed in [18] to cover the $0.69-0.97 \mathrm{GHz}$ and 2.3-3.32 GHz frequency bands.

In this paper, a novel slot antenna for mobile phone applications is presented. The antenna consists in a new version of the antenna presented in [18] featuring a smaller size and a wider bandwidth. The antenna is composed of two slots. The main slot, whose shape is a combination of a rectangle and of a circle, presents smaller width compared with the one in [18]. An additional slot having rectangular shape is employed to excite a resonance at the higher frequency band. The two slots are fed with a bent shape structure to obtain wideband impedance matching. The upper part of the board, at a distance of $3 \mathrm{~mm}$ above the slot, is folded vertically to the ground plane to reduce the antenna size. As a comparison 


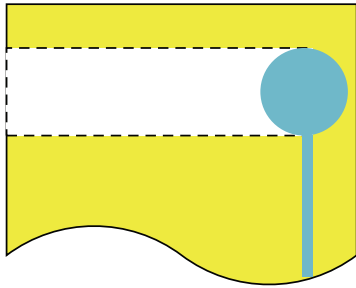

Ant1

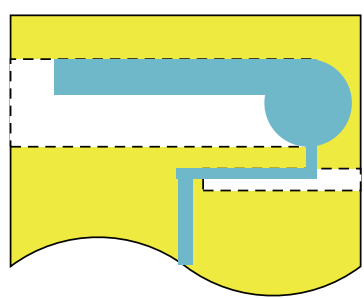

Ant4<smiles>CCCCCC</smiles>

Proposed antenna (see Figure 1)

FIGURE 2: Design evolution.

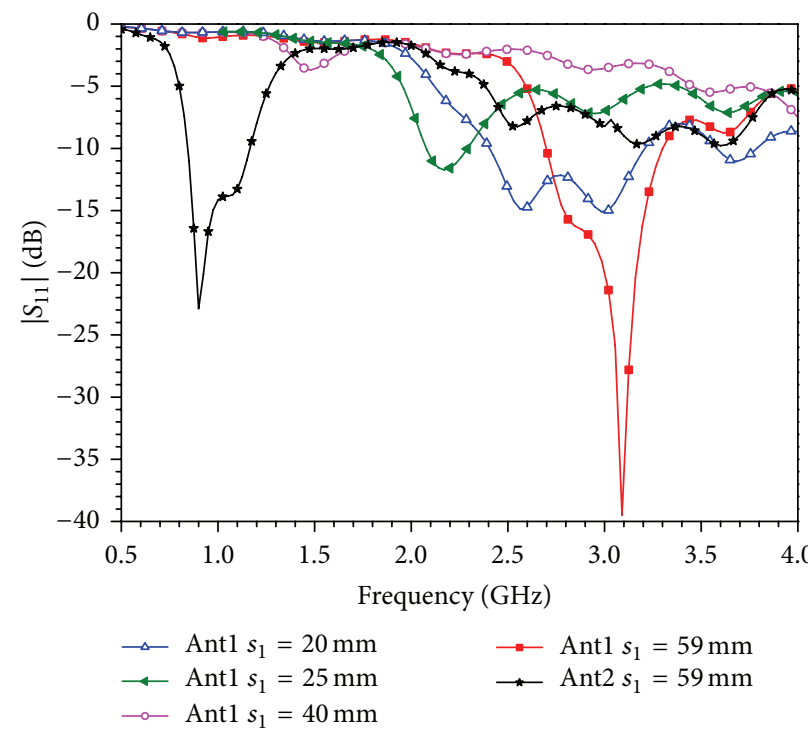

FIgURE 3: Frequency behavior of the parameter $\left|S_{11}\right|$ versus the slot length $s_{1}$ for Ant1 and Ant2.

in Table 1, the sizes and the bandwidths of the slot antennas available in the literature together with those proposed in the paper are reported.

\section{Antenna Design}

2.1. Antenna Configuration. The configuration of the proposed antenna is shown in Figure 1. The antenna is printed

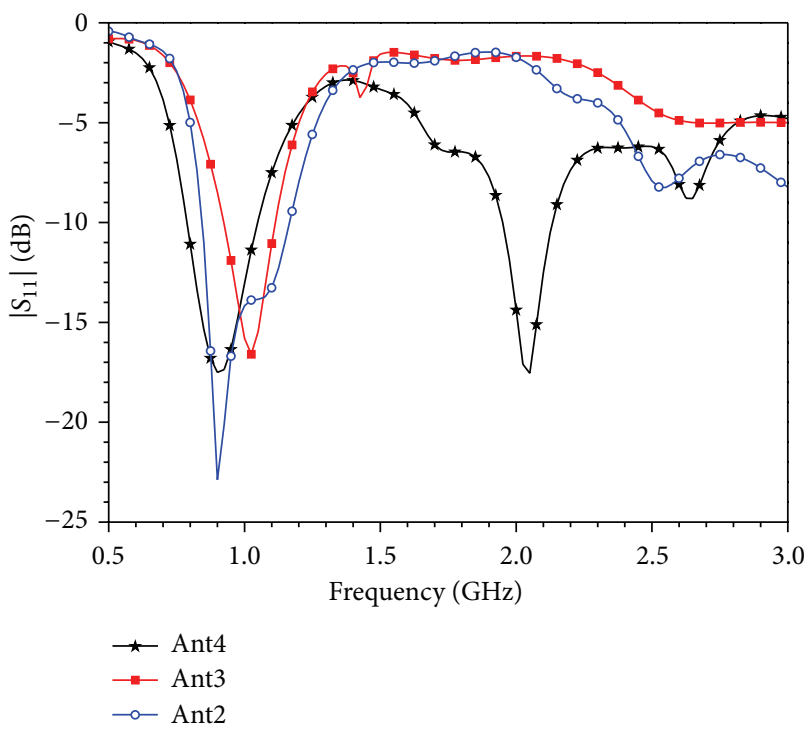

FIGURE 4: Frequency behavior of the parameter $\left|S_{11}\right|$ of Ant4 compared with that of Ant3 and Ant2.

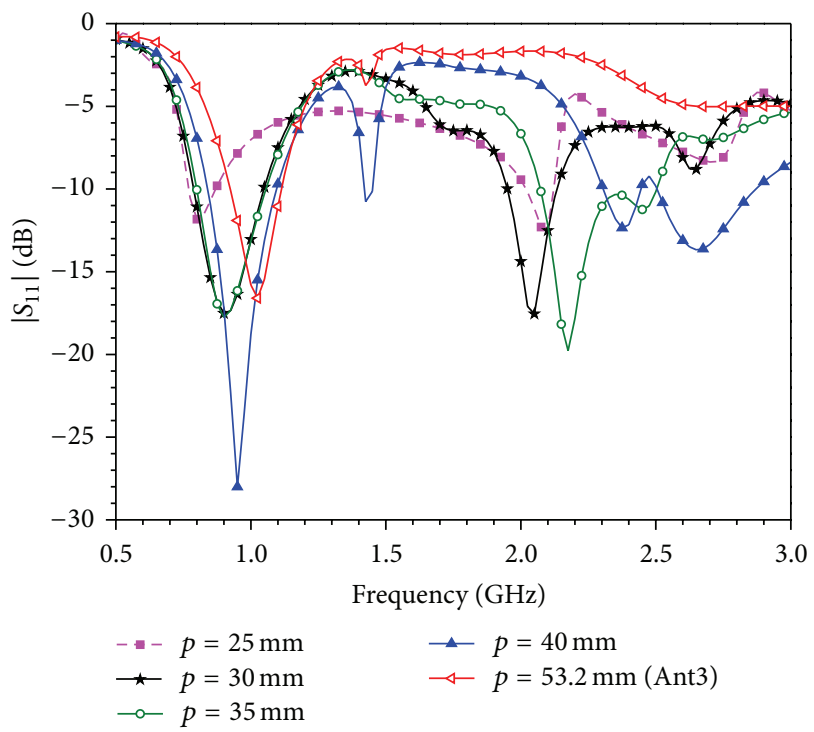

FIGURE 5: Frequency behavior of the parameter $\left|S_{11}\right|$ versus the parameter $p$ for Ant 4 .

on a $0.8 \mathrm{~mm}$ thick FR4 substrate with relative dielectric constant of 4.4 , loss tangent of 0.02 , and size of $60 \times 115 \mathrm{~mm}^{2}$. Two open-ended slots, called slot 1 and slot 2 , are etched at the opposite edges of the ground plane. Slot 1 with $10 \mathrm{~mm}$ width and total length of $59 \mathrm{~mm}$ is composed of a rectangle connected to a circle. Slot 2 has a rectangular shape with $2.8 \mathrm{~mm}$ width and $26 \mathrm{~mm}$ length. The two slots are excited by a rectangular monopole connected to a circular patch joined to a bent $50 \Omega$ microstrip line. The circular patch and slot have the same radius of $5 \mathrm{~mm}$, and the same center coordinates in the $y z$-plane. The footprints on the ground plane of the monopole and of the bent part of the feeding microstrip line are located within the slot regions (see Figure 2). The upper 


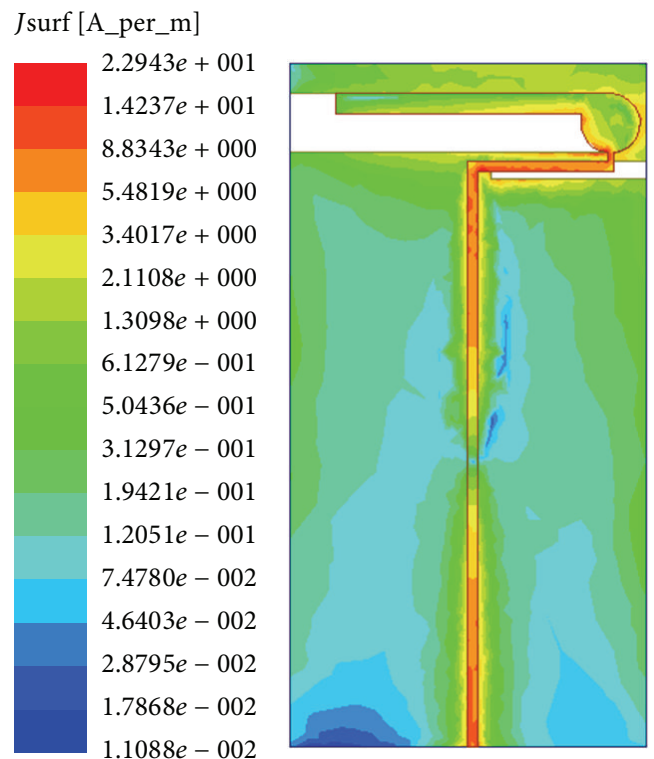

(a)

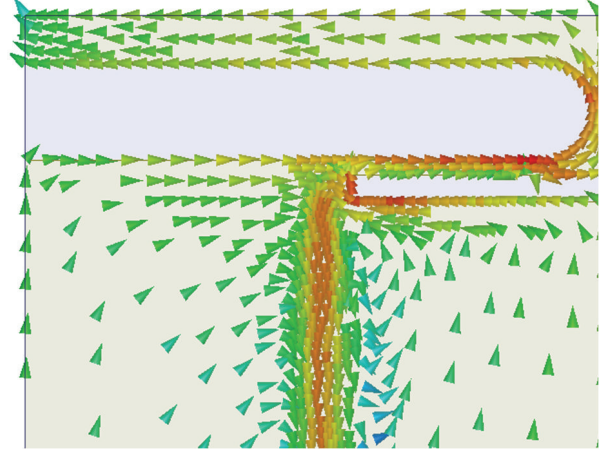

(b)

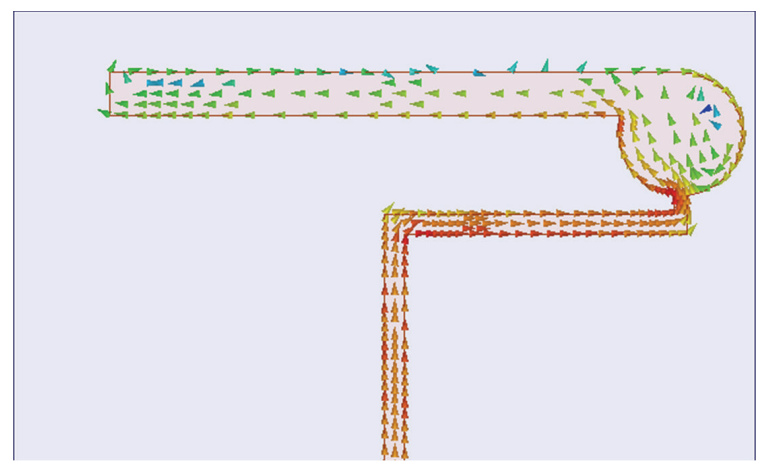

(c)

Figure 6: Simulated current distributions at $0.9 \mathrm{GHz}$. (a) Magnitudes of the surface current distributions on ground plane and top layer. (b) Vector representation on ground plane. (c) Vector representation on top layer.

TABLE 1: Comparison of the performance of the published slot antennas.

\begin{tabular}{|c|c|c|c|c|}
\hline Reference & PCB size $(\mathrm{mm} \times \mathrm{mm})$ & Slot size $(\mathrm{mm} \times \mathrm{mm})$ & Metal strip size $(\mathrm{mm} \times \mathrm{mm})$ & Bandwidth (MHz) \\
\hline$[9]$ & $40 \times 100$ & $15 \times 40$ & l & $822-962,1670-2670$ \\
\hline$[10]$ & $45 \times 121$ & $21 \times 45$ & l & 778-1070, 1674-2741 \\
\hline$[11]$ & $60 \times 110$ & $15 \times 51$ & l & $795-1035,1700-2205$ \\
\hline$[12]$ & $60 \times 115$ & $15 \times 50$ & $10 \times 60$ & $750-1040,1635-2485$ \\
\hline$[13]$ & $60 \times 115$ & $3.5 \times 40$ & $7 \times 60$ & $800-1300,1710-2325$ \\
\hline$[14]$ & $60 \times 105$ & $15 \times 59$ & l & $660-1065,1665-3000$ \\
\hline$[18]$ & $60 \times 115$ & $20 \times 59$ & l & $690-970,2300-3320$ \\
\hline Proposed & $60 \times 115$ & $14.3 \times 60$ & $3 \times 60$ & $698-1100,1640-2830$ \\
\hline
\end{tabular}

part of the board, at a distance of $3 \mathrm{~mm}$ above the slot, is folded vertically to the ground plane to reduce the antenna size. The antenna has been designed following the design steps indicated in Figure 2 as Ant1, Ant2, Ant3, Ant4, and the proposed antenna.

2.2. Ant1 and Ant2 Analyses. Antl has a radiating slot whose geometry consists in an open-ended rectangle and a closing semicircle. The slot is fed with a $50 \Omega$ microstrip line joined to a circular patch. Figure 3 shows the effect of slot length on $\left|S_{11}\right|$ of Antl. The numerical simulations were performed using the full-wave commercial software Ansys High Frequency Structure Simulator (HFSS) based on the finite-element method. It is seen that Antl obtains a wide bandwidth in the upper frequency band with a slot length of $s_{1}=20 \mathrm{~mm}$. A longer slot results in lower resonance 

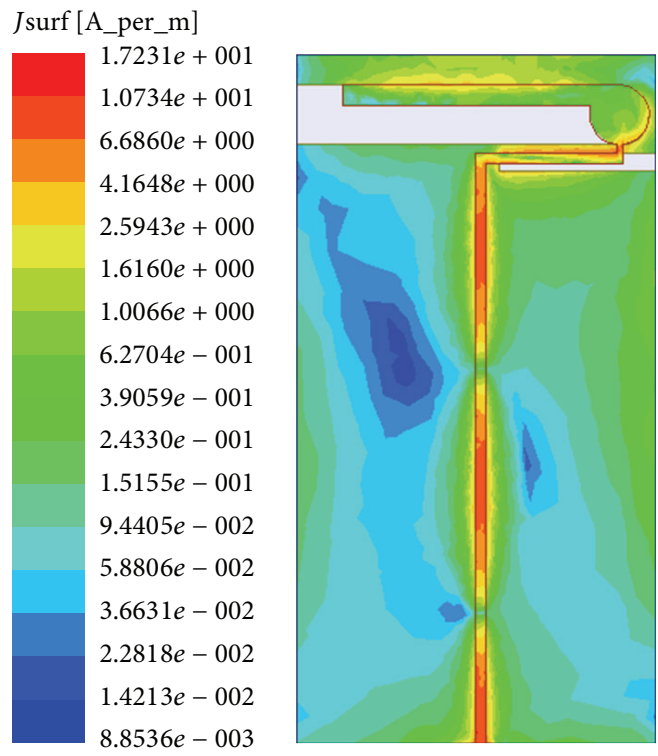

(a)

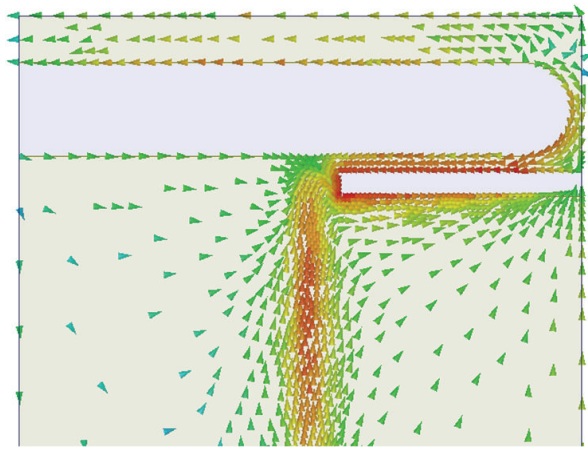

(b)

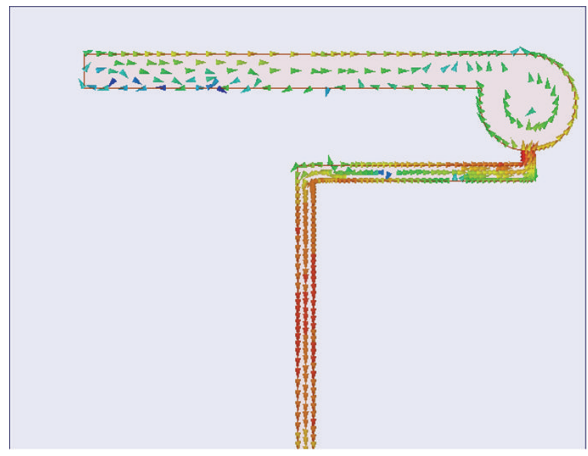

(c)

Figure 7: Simulated current distributions at $2 \mathrm{GHz}$. (a) Magnitudes of the surface current distributions on ground plane and top layer. (b) Vector representation on ground plane. (c) Vector representation on top layer.

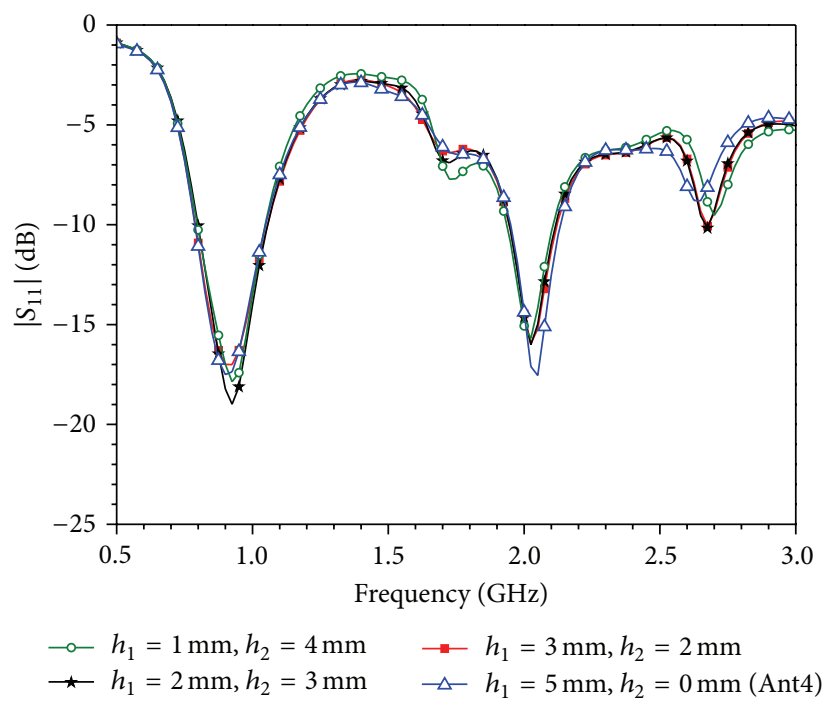

FIGURE 8: Frequency behavior of the parameter $\left|S_{11}\right|$ of the proposed antenna versus the geometrical parameters $h_{1}$ and $h_{2}$.
TABLE 2: Resonant frequencies and bandwidths of Ant1 and Ant2 for different values of the slot lengths $s_{1}$.

\begin{tabular}{lccc}
\hline Antenna & $s_{1}(\mathrm{~mm})$ & $\begin{array}{c}\text { Antenna first } \\
\text { resonant frequency } \\
(\mathrm{GHz})\end{array}$ & $\begin{array}{c}\text { Bandwidth of } \\
\text { the first resonant } \\
\text { mode }(\mathrm{GHz})\end{array}$ \\
\hline Ant1 & 20 & 2.6 & $2.2-4$ \\
Ant1 & 25 & 2.16 & $1.9-2.5$ \\
Ant1 & 40 & 1.48 & $/$ \\
Ant1 & 59 & 0.95 & $/$ \\
Ant2 & 59 & 0.9 & $0.82-1.23$ \\
\hline
\end{tabular}

but worse $\left|S_{11}\right|$. Table 2 gives the resonant frequencies and bandwidths of the first resonant modes for different values of the slot length $s_{1}$. The resonant frequency shifts to the lower frequencies and the bandwidth decreases as the parameter $s_{1}$ increases. From Figure 3, it appears that, in the cases of 


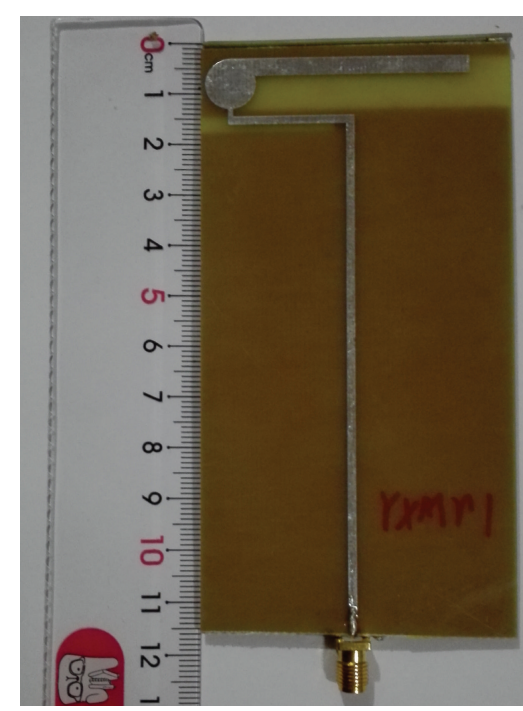

(a)

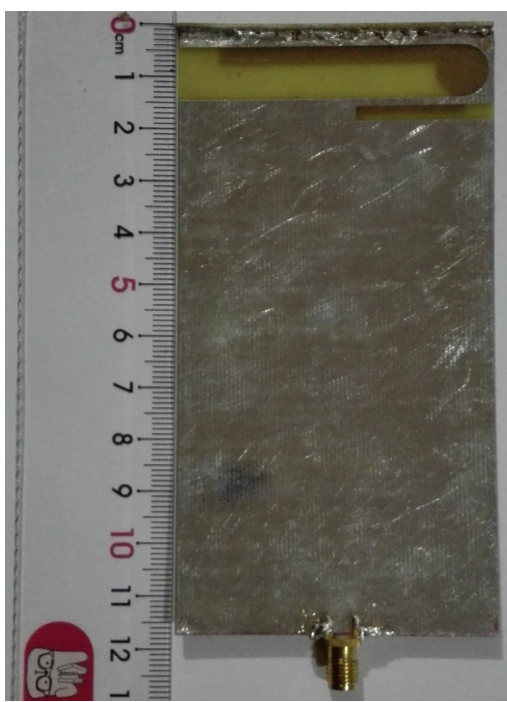

(b)

Figure 9: Photographs of the fabricated antenna. (a) Front view. (b) Back view.

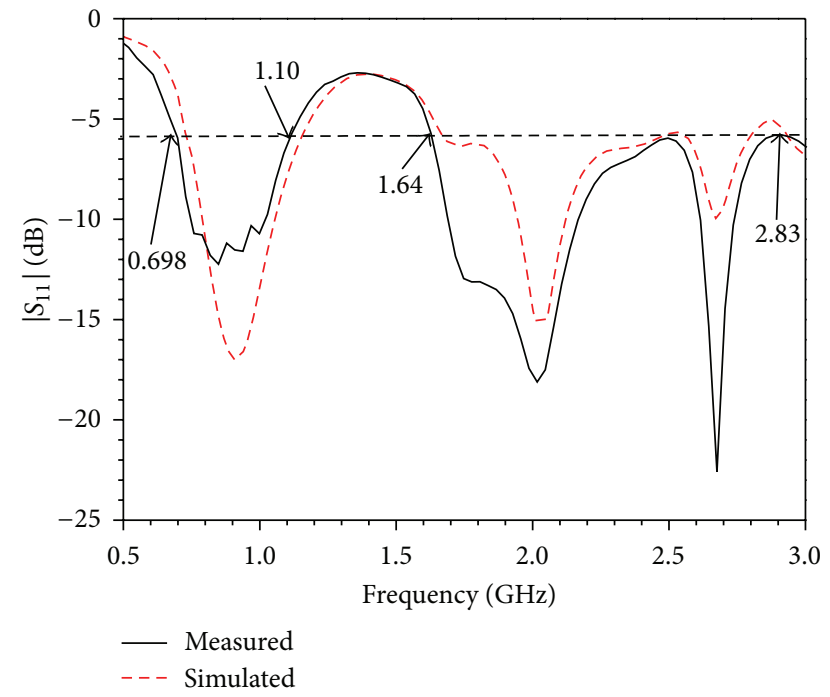

Figure 10: Frequency behavior of the parameter $\left|S_{11}\right|$ of the proposed antenna.

$s_{1}=40$ and $59 \mathrm{~mm}$, the parameter $\left|S_{11}\right|$ at the first resonant frequencies is worse than $-6 \mathrm{~dB}$.

To cover the lower band below $1 \mathrm{GHz}$, a long slot with a length of $59 \mathrm{~mm}$ is preferred. Impedance matching structure is required to reduce $\left|S_{11}\right|$ of the first resonant mode. To this end, the feeding structure of Ant1 has been modified by adding a rectangular monopole to the end of the circular patch, giving rise to the antenna configuration identified as Ant2. In this design configuration the footprint of rectangular monopole falls inside the rectangular slot with its termination pointing toward the open end of the rectangular slot. In this way some current flow is excited around the slot realized on the ground plane. The optimized bandwidths for Ant2 are $0.82-1.23 \mathrm{GHz}$ and $2.43-3.83 \mathrm{GHz}$. The left cutoff frequencies

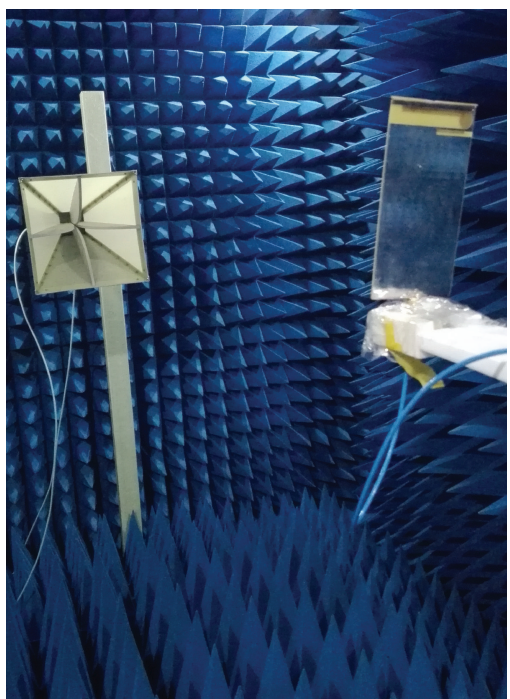

FIGURE 11: Antenna within the microwave anechoic chamber. The measurement setup adopted to measure the antenna radiation patterns can be observed.

for lower and upper bands are still too high to cover LTE700, GSM1800/1900, and UMTS. Thus, another slot (slot 2) having rectangular shape is added at Ant2 to adjust the bandwidth.

2.3. Ant3 Analysis and Ant4 Design. Ant3 is obtained by adding slot 2 directly below the main radiating slot of Ant2. Ant 4 is finally obtained by moving the location of the microstrip line to the left side and bending it so that it results distributed along slot 2 (see Figure 2). Figure 4 shows the comparison of $\left|S_{11}\right|$ of the three antennas. It is seen that Ant3 has worse $\left|S_{11}\right|$ and narrower bandwidth than Ant2. The adoption of slot 2 worsens the antenna's matching. A 


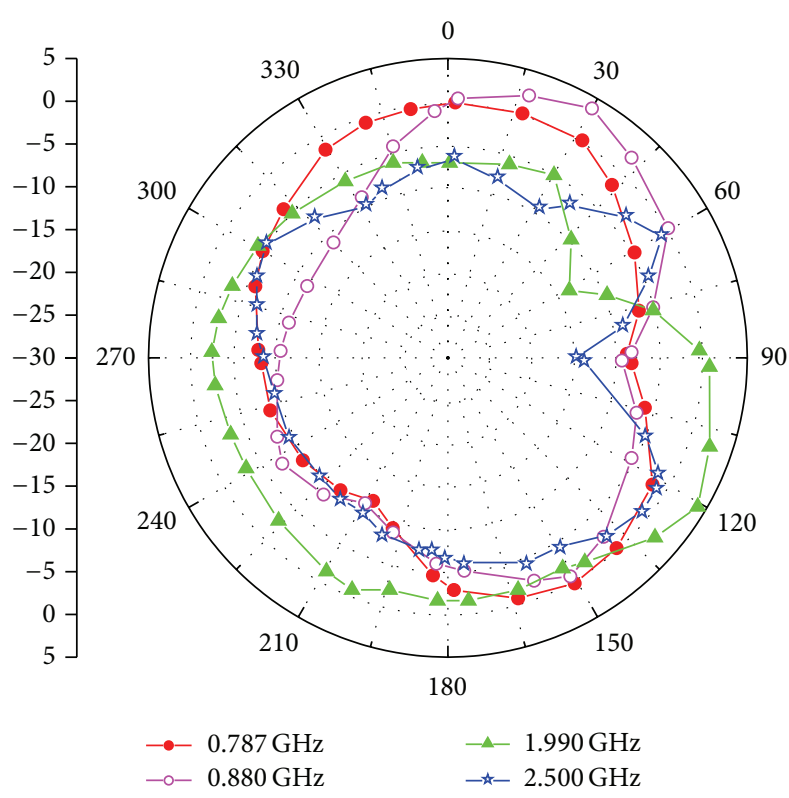

(a)

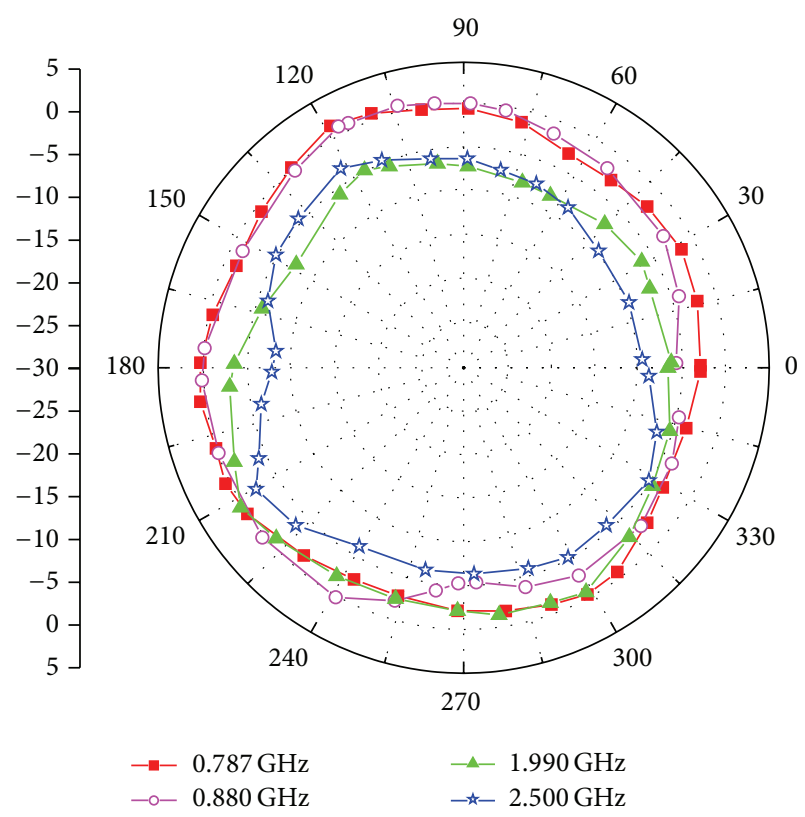

(b)

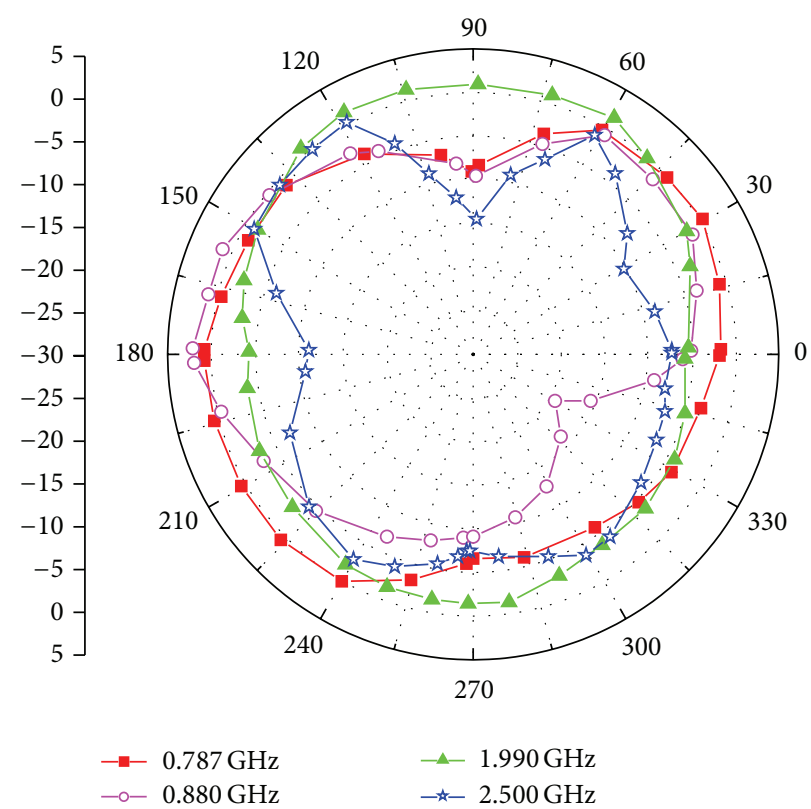

(c)

FIGURE 12: Measured radiation gain pattern (dBi). (a) $x y$-plane. (b) $x z$-plane. (c) $y z$-plane.

wider bandwidth and a frequency left-shifting are obtained simultaneously by a modification of the feeding microstrip location. The simulated $-6 \mathrm{~dB}$ bandwidths of Ant 4 cover the frequency bands $0.71-1.12 \mathrm{GHz}$ and $1.70-2.73 \mathrm{GHz}$.

Figure 5 shows the effect of the feeding position $p$ on the parameter $\left|S_{11}\right|$. It is seen that, by shifting the microstrip feeding line from the right corner $(p=53.2 \mathrm{~mm})$ to the center of the board ( $p=30 \mathrm{~mm}$ ), the $-6 \mathrm{~dB}$ bands move to lower frequency. Moreover, a further shifting of the feeding line $(p=25 \mathrm{~mm})$ results in a narrower bandwidth of the higher frequency band. Therefore, $p=30 \mathrm{~mm}$ is chosen being the optimal value.

The surface currents excited at $0.9 \mathrm{GHz}$ and $2 \mathrm{GHz}$ on the metal surfaces of the monopole and of the ground plane are shown in Figures 6 and 7. From these figures it appears that on the monopole a significant level of surface current is excited at both frequencies, while the current flowing along the edges of slot 2 is for exciting a slot field useful to the compensation of the reactive component of the antenna input impedance with a consequent widening of the antenna bandwidth [19]. 
Finally, a higher surface current level is excited on the ground plane at the frequency of $0.9 \mathrm{GHz}$.

2.4. The Proposed Antenna Design. To reduce the antenna size, the upper part above the main slot is folded vertically to the board obtaining the final configuration of the proposed antenna. In order to determine the extension of the fold, identified by the parameter $h_{2}$, the frequency behavior of the parameter $\left|S_{11}\right|$ has been investigated (see Figure 8). It is seen that folding the board has negligible effect on the antenna bandwidth. However, at frequencies around $2.5 \mathrm{GHz}$ the parameter $\left|S_{11}\right|$ becomes a little bit worse as the folded parameter $h_{2}$ is increased. To balance the performances of size reduction and wide bandwidth, $h_{2}=3 \mathrm{~mm}$ and $h_{1}=2 \mathrm{~mm}$ are chosen.

\section{Experiments and Discussion}

The proposed antenna, whose prototype is shown in Figure 9, was fabricated and measured. The simulated and measured values of the parameter $\left|S_{11}\right|$ are shown in Figure 10. The measurements were performed with an Agilent vector network analyzer N5224A in an ordinary laboratory without any microwave absorbers. As shown in Figure 10, there is a slight disagreement between measurement and simulation, which is mainly caused by the SMA connector adopted to excite the antenna. The measured bandwidths at $-6 \mathrm{~dB}$ are in the frequency bands $0.698-1.10 \mathrm{GHz}$ and $1.64-2.83 \mathrm{GHz}$, thus covering the LTE700/2300/2500, GSM850/900/1800/1900, and UMTS bands.

The radiation patterns were measured in a microwave anechoic chamber. The measurement environment is shown in Figure 11. Figure 12 shows the measured radiation pattern in the $x y$-, $x z$-, and $y z$-planes at $0.787,0.88,1.99$, and $2.5 \mathrm{GHz}$. The patterns are omnidirectional in the $x z$-plane and nearomnidirectional in the $x y$-plane. The maximum gains at the four frequencies are $1.53,2.91,3.36$, and $0.85 \mathrm{dBi}$, respectively. The antenna meets the directional requirement of mobile phones.

\section{Conclusion}

A low profile printed antenna formed by two slots and a suitable monopole used as exciter has been proposed. A circular shape has been adopted in the slot and in the feeding structures. To match the antenna, the feeding microstrip line has been folded keeping the folded sections parallel to the slots. The measurements performed on the antenna prototype confirm that the antenna is suitable to cover the LTE700/2300/2500, GSM850/900/1800/1900, and UMTS bands with near-omnidirectional radiation patterns. In conclusion, on the basis of the electrical characteristics, the small size and low profile, the antenna becomes suitable for smart phone applications.

\section{Competing Interests}

The authors declare that they have no competing interests.

\section{Acknowledgments}

This work was supported in part by the Natural Science Foundation of China (nos. 61501277 and 61307050) and Shandong Province Higher Educational Science and Technology Program (no. J14LN86).

\section{References}

[1] K.-L. Wong and P.-R. Wu, "Dual-wideband linear open slot antenna with two open ends for the LTE/WWAN smartphone," Microwave and Optical Technology Letters, vol. 57, no. 6, pp. 1269-1274, 2015

[2] K.-L. Wong and Y.-J. Li, "Low-profile open-slot antenna with three branch slots for triple-wideband LTE operation in the metal-framed smartphone," Microwave and Optical Technology Letters, vol. 57, no. 10, pp. 2231-2238, 2015.

[3] J. Lee, Y. Liu, and H. Kim, "Mobile antenna using multiresonance feed structure for wideband operation," IEEE Transactions on Antennas and Propagation, vol. 62, no. 11, pp. 5851$5855,2014$.

[4] S. W. Lee, H. S. Jung, and Y. J. Sung, "A reconfigurable antenna for LTE/WWAN mobile handset applications," IEEE Antennas and Wireless Propagation Letters, vol. 14, pp. 48-51, 2015.

[5] C. Yoon, S.-G. Hwang, G.-C. Lee, W.-S. Kim, H.-C. Lee, and H.D. Park, "A reconfigurable antenna using varactor diode for LTE MIMO applications," Microwave and Optical Technology Letters, vol. 55, no. 5, pp. 1141-1145, 2013.

[6] S. W. Lee and Y. Sung, "Compact frequency reconfigurable antenna for LTE/WWAN mobile handset applications," IEEE Transactions on Antennas and Propagation, vol. 63, no. 10, pp. 4572-4577, 2015.

[7] J. H. Lee and Y. Sung, "Reconfigurable hexa-band planar inverted-F antenna using a PIN diode for mobile handset," Microwave and Optical Technology Letters, vol. 55, no. 8, pp. 1926-1928, 2013.

[8] S. M. Ali and K. Payandehjoo, "Tunable antenna techniques for compact handset applications," IET Microwaves, Antennas and Propagation, vol. 8, no. 6, pp. 401-408, 2014.

[9] C.-I. Lin and K.-L. Wong, "Printed monopole slot antenna for internal multiband mobile phone antenna," IEEE Transactions on Antennas and Propagation, vol. 55, no. 12, pp. 3690-3697, 2007.

[10] C.-H. Wu and K.-L. Wong, "Hexa-band internal printed slot antenna for mobile phone application," Microwave and Optical Technology Letters, vol. 50, no. 1, pp. 35-38, 2008.

[11] S.-L. Zuo, Z.-Y. Zhang, and J.-J. Xie, "Design of dual-monopole slots antenna integrated with monopole strip for wireless wide area network mobile handset," IET Microwaves, Antennas and Propagation, vol. 8, no. 3, pp. 194-199, 2014.

[12] K.-L. Wong, P.-W. Lin, and C.-H. Chang, "Simple printed monopole slot antenna for penta-band wireless wide area network operation in the mobile handset," Microwave and Optical Technology Letters, vol. 53, no. 6, pp. 1399-1404, 2011.

[13] C.-H. Chang, W.-C. Wei, P.-J. Ma, and S.-Y. Huang, "Simple printed WWAN monopole slot antenna with parasitic shorted strips for slim mobile phone application," Microwave and Optical Technology Letters, vol. 55, no. 12, pp. 2835-2841, 2013.

[14] C. Deng, Y. Li, Z. Zhang, and Z. Feng, "Planar printed multiresonant antenna for octa-band WWAN/LTE mobile handset," IEEE Antennas and Wireless Propagation Letters, vol. 14, pp. 1734-1737, 2015. 
[15] W.-S. Chen and C.-H. Lin, "A planar hybrid antenna for UWB application," Microwave and Optical Technology Letters, vol. 51, no. 5, pp. 1243-1246, 2009.

[16] W.-H. Zong, X.-Y. Qu, Y.-X. Guo, and M.-X. Shao, "An ultrawideband antenna for mobile handset applications," Advanced Materials Research, vol. 383-390, pp. 4457-4460, 2012.

[17] Z. Guo, H. Tian, X. Wang, Q. Luo, and Y. Ji, "Bandwidth enhancement of monopole UWB antenna with new slots and ebg structures," IEEE Antennas and Wireless Propagation Letters, vol. 12, pp. 1550-1553, 2013.

[18] W. H. Zong, X. M. Yang, S. D Li, X. Y. Wei, and J. C. Hou, "Design and fabrication of a wideband slot antenna for Handset Applications," in Proceedings of the IEEE International RF and Microwave Conference (RFM '15), Kuching, Malaysia, December 2015.

[19] D. Caratelli, R. Cicchetti, G. Bit-Babik, and A. Faraone, "Circuit model and near-field behavior of a novel patch antenna for WWLAN applications," Microwave and Optical Technology Letters, vol. 49, no. 1, pp. 97-100, 2007. 


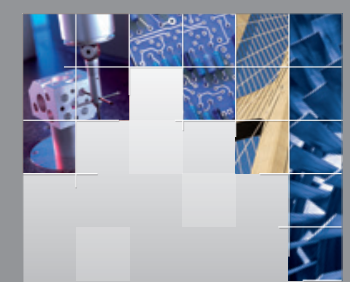

\section{Enfincering}
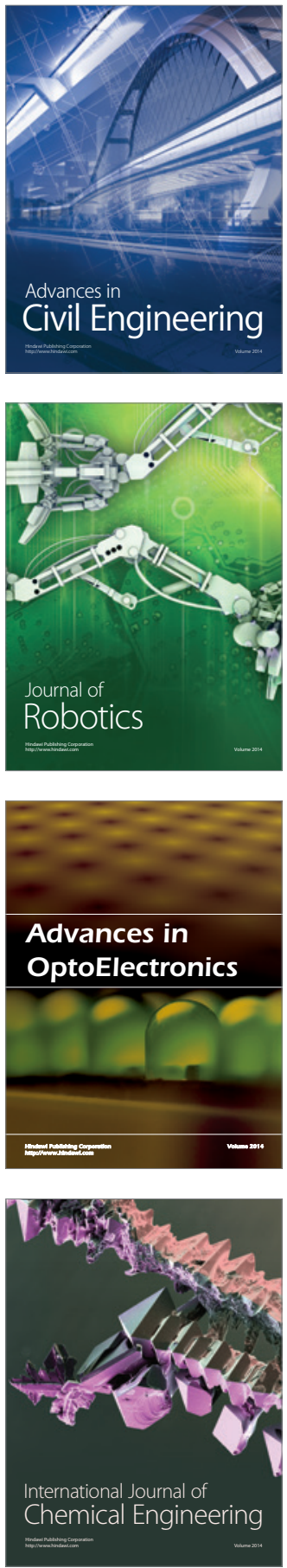

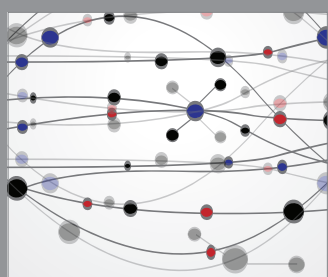

The Scientific World Journal

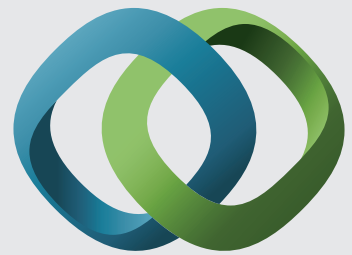

\section{Hindawi}

Submit your manuscripts at

http://www.hindawi.com
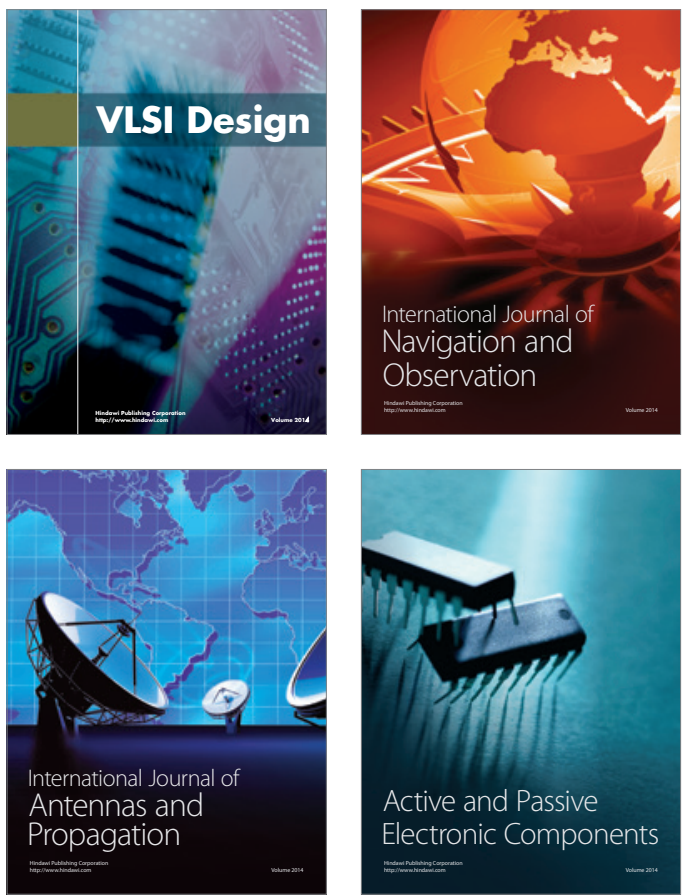
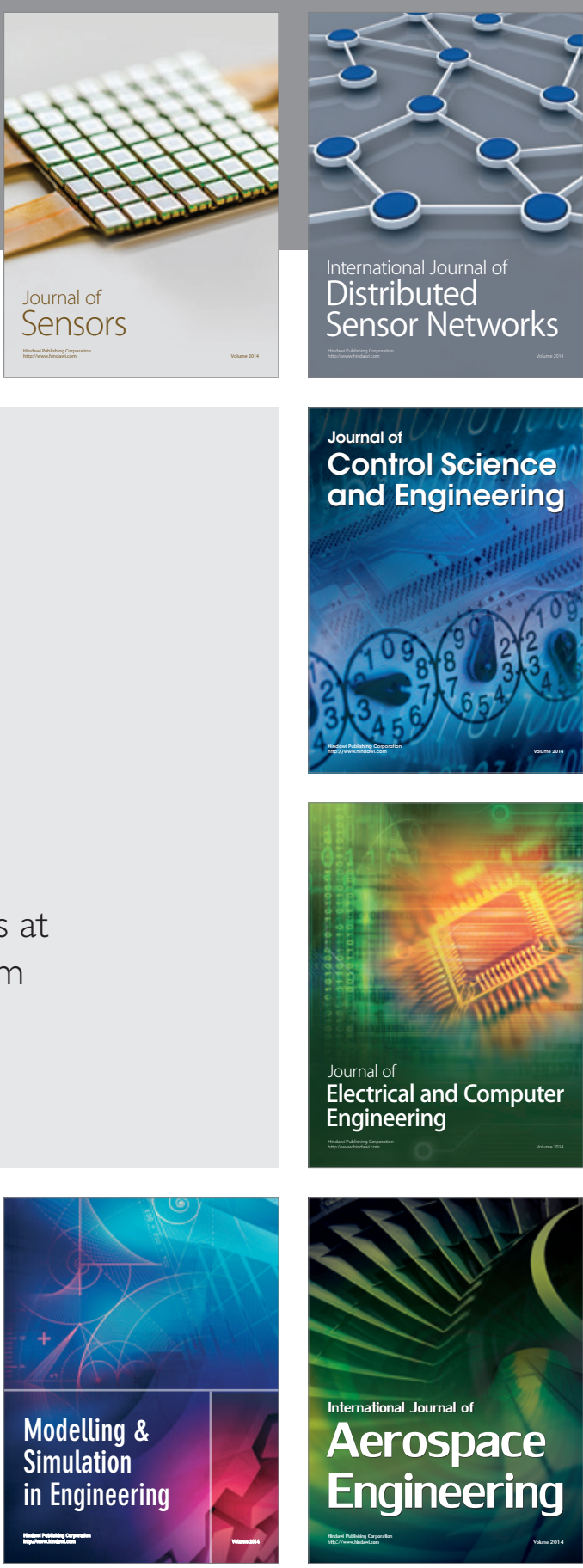

International Journal of

Distributed

Sensor Networks

Journal of

Control Science

and Engineering
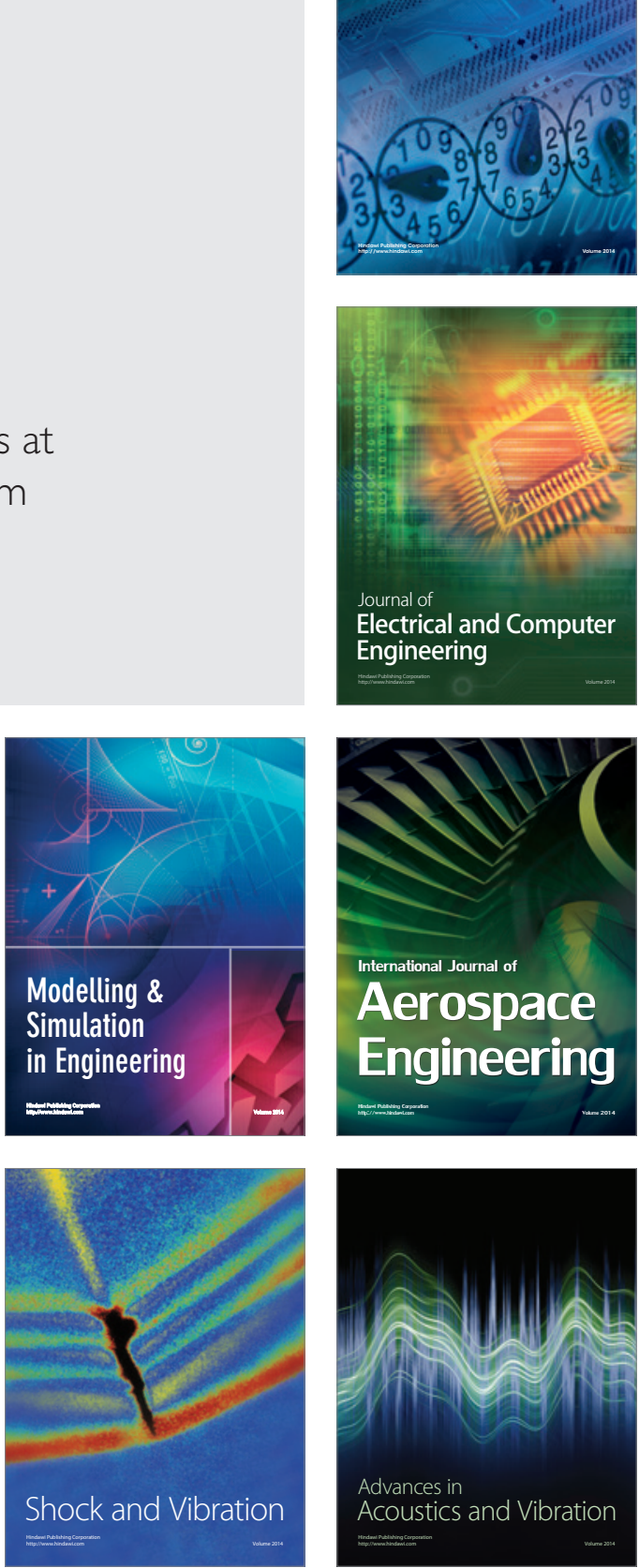